\title{
Nexus of COVID-19 and carbon prices in the EU emission trading system: evidence from multifractal and the wavelet coherence approaches
}

\author{
Majid Mirzaee Ghazani ${ }^{1}$ [D $\cdot$ Reza Khosravi ${ }^{1} \cdot$ Sasan Barak ${ }^{2}$
}

Received: 18 October 2021 / Accepted: 20 December 2021 / Published online: 28 January 2022

(c) The Author(s), under exclusive licence to Springer-Verlag GmbH Germany, part of Springer Nature 2021

\begin{abstract}
In this paper, we analyzed the role of carbon pricing as a vital tool for achieving the sustainable energy transition and discussed policy implications for reaching this goal in the era of the COVID-19 pandemic. To investigate the connection and cross-correlation between COVID-19 cases and carbon price returns in EU ETS, we applied two novel approaches: the multifractal detrending moving average cross-correlation (MF-X-DMA) and the wavelet coherence techniques. The coverage of data is from 2 March 2020 to 19 March 2021. The results of the MF-X-DMA method show that the cross-correlation is substantial and negatively correlated. Moreover, the results imply the presence of multifractal cross-correlations and that a significant change in the number of COVID-19 cases further impacts carbon price fluctuations. Concerning the wavelet coherence method results, we can also find a strong (negative) relationship between selected variables, and this strong correlation is observed throughout the whole study period. In addition, we observe that in the first wave of the COVID-19 outbreak, the changes in the COVID-19 cases are leading the $\mathrm{CO}_{2}$ price returns (particularly in the 16-32 time scale). The results of this study can have significant implications for policymakers and contributions for environmental experts and investors.
\end{abstract}

Keywords COVID-19 $\cdot$ Carbon pricing $\cdot$ EU ETS $\cdot$ Cross-correlation analysis $\cdot$ Multifractal detrending moving average Wavelet analysis

\section{Introduction}

The COVID-19 pandemic has unleashed exceptional shocks through all facets of society, from strained healthcare systems to the closure of economies. In the meantime, the lockdowns, as an excessive phenomenon, initiated a severe recession in many economies (OECD 2020). The global economic outcomes of the COVID-19 pandemic were dramatic, and it brought the world's economy to an impasse circumstance. The International Monetary Fund (IMF) predicted that global GDP shrank by $3.3 \%$ in 2020 , far more significant

Responsible Editor: Nicholas Apergis

Majid Mirzaee Ghazani

majidmirzaee@kntu.ac.ir

1 Department of Industrial Engineering, K. N. Toosi

University of Technology, Tehran, Iran

2 Department of Decision Analytics and Risk, Southampton Business School, University of Southampton, Southampton, UK than during the 2008-2009 Global Financial Crisis, while it anticipated an even more reduction of $5.8 \%$ for the Euro Area (IMF 2021).

In the meantime, the lockdowns triggered by the COVID19 pandemic have significantly altered energy consumption patterns and lowered $\mathrm{CO}_{2}$ emissions worldwide. The lockdowns and the related downfall of economic activity have initiated considerable mitigations in greenhouse gas (GHG) emissions from transportation and industrial activity. The International Energy Agency (IEA) believes that global $\mathrm{CO}_{2}$ emissions ebbed by $8 \%$ in 2020 (IEA 2020). Recent data issued by the IMF and IEA for 2020 predict emissions will bounce back in 2021. However, the full effect of COVID-19 in terms of how long the disaster will be and how the consumption pattern of energy and the associated levels of $\mathrm{CO}_{2}$ emissions will be affected is unclear. The energy sector is no exception, with several considerations being raised about the consequences of the clean energy transition (Dechezlepretre et al. 2020). In response, policymakers worldwide have participated in arrangements for controlling and holding the contagious virus back (e.g., delivering adequate healthcare, 
vaccination, and avoiding economic downfall by instigating stimulus packages) (Hale et al. 2020). However, with the emergence of new strains of the COVID-19 (such as Delta variant), and even after vaccination, the number of cases has increased again recently, and strict measures taken to control the spread of the virus (e.g., new lockdowns and travel restrictions). Therefore, despite the initial expectation of a rapid recovery in economic conditions, the outlook for economic growth has now adjusted downward. For example, in the latest assessment of the global economic condition, the IMF has predicted that the global economic recovery may have peaked, especially as sporadic Delta outbreaks continue to flare across different countries (IMF, World Economic Outlook Update, 2021).

Moreover, the analysis carried out by Carbon Brief has concluded that the pandemic initiated the largest ever annual reduction in $\mathrm{CO}_{2}$ emissions (Evans 2020). Energy emissions contribute $60 \%$ of total GHG emissions, so the energy sector needs to decrease its carbon footprint to back climate change mitigation attempts across the energy supply chain. In all scenarios, $\mathrm{CO}_{2}$ emissions are the dominant environmental constraint (UNECE 2020). Accordingly, it is essential to pay attention to policies and approaches that help us achieve indispensable goals such as (sustainable) energy transitions in critical situations (e.g., the COVID-19 pandemic) with considering such environmental constraints.

In the meantime, the European Union (EU) has developed several valuable tools to support the energy transition, and the emission trading system (ETS) is one of the key ones in this area. Therefore, we focused on the EU ETS as one of the world's largest carbon markets which plays a pivotal role in achieving the energy transition (especially during the COVID19 pandemic). The EU ETS is arranged as the first and the essential $\mathrm{CO}_{2}$ market globally and still one of the leading capand-trade schemes pursuing emission reduction. The EU ETS is the foundation of the EU's attempts to relieve climate change and the principal framework for minimizing GHG emissions among different sectors like power, industrial, and aviation (European Commission, 2018). Also, it is enveloping more than $40 \%$ of the EU's GHG emissions and accounts for over $75 \%$ of international $\mathrm{CO}_{2}$ trading (Mirzaee Ghazani and Jafari 2021).

By looking at the historical development of EU ETS, 2020 was a crucial year due to the following reasons: the declaration of landmark climate policy schemes in the context of the European Green Deal; the completion of the governing provisions in advance of Phase IV (2021-2030); and a marketplace that demonstrated its resilient against economic shocks triggered by the COVID-19 contagion. One of the ideas suggested in recent years is the Climate Law and the Climate Target Plan (2030) that heralds for sharper emissions cutbacks and expect to realize the EU ETS perform a principal task in Europe's decarbonization policy. Other possibilities, e.g., to tackle the threat of carbon leakage, are also deliberated - embracing a carbon border adjustment tool focusing on particular industrial sectors (ICAP 2021). In this regard, developments in selected ETSs are illustrated in Fig. 1. Emphasized dates specify the initial critical announcements by the governments concerning limitations to halt the dissemination of COVID-19. Even though most of the presented schemes faced an exceptional price reduction in the early period of the COVID-19 pandemic, prices were retrieved for most ETSs through the second half of 2020. The slump in production levels contributes to a severe reduction in demand for allowances, which has caused the prices to tumble significantly now and possibly the incentives for any investment in clean energy technologies in the future. However, the professionals consider that the recent fall in the GHGs because of COVID-19 will be a transitory period, and as soon as the global economies start to improve and recover production levels, the carbon emissions are expected to come back to normal (Mintz-Woo et al. 2020).

On the other hand, the pandemic happened at a crucial juncture regarding the connection between politics and (sustainable) energy transitions. Policymakers and economic agents are displaying a growing consent in the principal role of carbon pricing in the transition towards a decarbonized economy. However, by examining the literature, we are witnessing the apparent lack of studies that analyzed the impact of the COVID-19 outbreak on carbon market developments (despite its pivotal role in achieving (sustainable) energy transitions) and any interconnection between them. Therefore, it is necessary to conduct studies in this area.

The contributions of this research are threefold. First, this study scrutinizes the impact of the COVID-19 pandemic on sustainable energy transition and its influence on the carbon market as one of the critical tools for achieving this aim with considering the relevant policy implications. Second, we examined the (cross)-correlation between the COVID-19 cases in the EU and returns of carbon allowances in EU ETS by applying the MF-X-DMA technique. Third, we employed the wavelet coherence analysis to discover the co-movement between two time series in a joint time-frequency domain.

The remainder of this research is structured as follows: Section 2 presents the study's literature review. Section 3 shows the data and the methods implemented in the study. The assessment of the outcomes has been exhibited in Section 4. The policy implications for the current study have been mentioned in Section 5, and ultimately, Section 6 concludes the study.

\section{Literature review}

By investigating the literature on the COVID-19 pandemic and its interconnections with economic factors (e.g., financial assets, macroeconomic variables), several studies took 


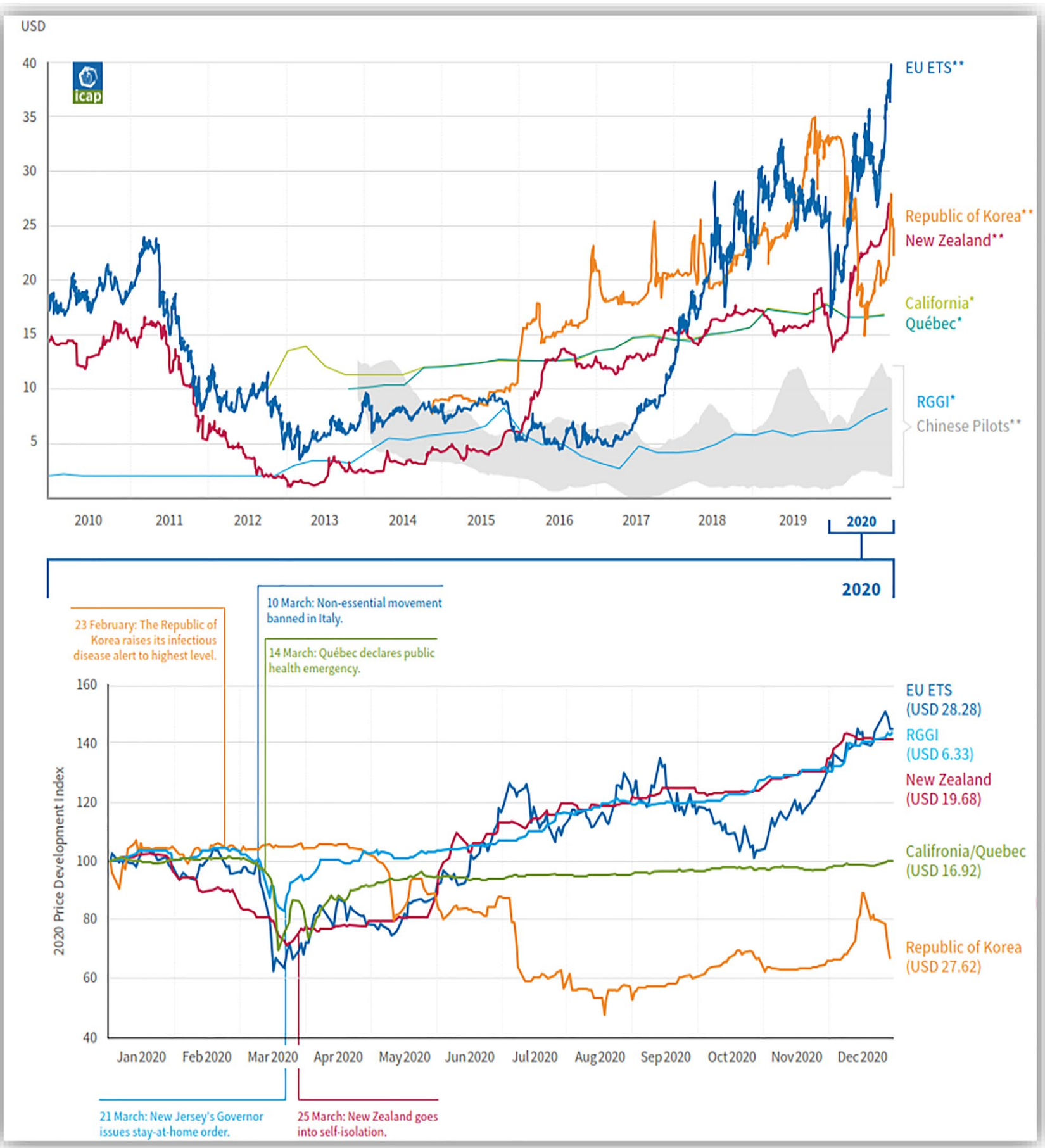

Fig. 1 Price developments in primary $(*)$ and secondary $(* *)$ markets $(2010-2020)$ in major ETSs and index of allowance prices in selected ETSs exclusively in 2020 ( source: ICAP 2021)

place in this area and applied different approaches for analyzing the issue. Regrading, we distinguished and classified the studies on three distinct categories: (I) studies that focused on the issue of (sustainable) energy transition in the era of COVID-19 contagious (Aktar et al. 2021; Hosseini 2020; Jiang et al. 2021; Klenert et al. 2020; Kuzemko et al. 2020), (II) studies that have dealt with the subject of COVID-19 and environmental issues(Aljadani et al. 2021; Andreoni 2021; Hauser et al. 2021; Meles et al. 2020; Sikarwar et al. 2021; Smith et al. 2021), and (III) two different kinds of studies that implemented the analytical methods including the studies that applied the multifractal analysis 
(Choi 2021; Mensi et al. 2021; Naeem et al. 2021) and the wavelet (coherence) approach (Chien et al. 2021; Goodell and Goutte 2021; Karamti and Belhassine 2021; Sharma et al. 2021). In what follows, we attempted to examine the ideas offered in all of the mentioned studies.

\section{COVID-19 and (sustainable) energy transition}

Hosseini (2020) argued that the outburst of the COVID19 conquered the globe and its effects are expected to be much more prevalent over time, directly and indirectly. The COVID-19 crisis has hit the supply chain of facilities that focused on renewable energy manufacturing and hindered the transition to sustainable energy in the world. Thus, the climate and energy policies may need to be reorganized based on the new situations. Finally, he concluded that the logical policies could change the threats of COVID-19 to the exceptional opportunities for the renewable energies sector.

Kuzemko et al. (2020) employed several groups of researchers in the field of social science to analyze the consequences of COVID-19 for the politics of sustainable energy transitions. They recognized some of the direct effects of the "extreme lockdown" on sustainable and fossil energy sources. They concluded that the politics of sustainable energy transitions are now at a crucial moment, where the shape and way of national provision for post-pandemic economic retrieval will be decisive. Klenert et al. (2020) stated that the nexus of COVID-19 and climate change has so far brought attention to short-term GHG emissions reductions, public health responses, and clean recovery stimulus packages. They concluded that learning from policy challenges during the COVID-19 crisis could enhance efforts to reduce GHG emissions and prepare humanity for future crises.

Aktar et al. (2021) analyzed how the policymakers navigate the impacts of the COVID-19 pandemic on climate change policies. They proposed considering a comprehensive and resounding overview of the observed facts. Finally, this research sketched policy implications that can be utilized as a guideline for the situations like the current one in which uncertainty is amplified.

Jiang et al. (2021) overviewed the effects and challenges of COVID-19 on energy demand and underlined energyrelated lessons and arising prospects. Also, the obtained results show noticeable variations in the energy intensity; the further energy for fighting against COVID-19 is significant for balancing energy demand and the recovery in the energy sector. They concluded that this research could suggest a new way to open innovative methods for boosting energy efficiency, encouraging energy-saving, and discovering emerging opportunities in the energy sector for the post-COVID-19 situation.

\section{COVID-19 and environmental issues}

Looking at the literature, we can observe that several studies focus on the relationship between $\mathrm{CO}_{2}$ emission and different economic factors. For example, we can refer to the study of Asongu et al. (2016) that analyzed the interconnection between energy consumption, $\mathrm{CO}_{2}$ emissions, and economic growth (GDP) in 24 African countries by applying a panel autoregressive distributed lag (ARDL) method. The findings in this study are as follows: Firstly, a long-run relationship between EC, CE, and GDP is detectable. Secondly, a long-term effect from $\mathrm{CO}_{2}$ emissions to GDP and energy consumption is noticeable, with mutual directions. Furthermore, they mentioned that causality runs from either $\mathrm{CO}_{2}$ emissions or $\mathrm{CO}_{2}$ emissions and energy consumption to GDP and opposite causal directions are noticeable.

However, studies have turned to this area after the onset of the COVID-19 pandemic. Therefore, we discussed some of the proposed studies in the following: Smith et al. (2021) evaluated the consequence of the COVID-19 pandemic on world fossil fuel consumption and $\mathrm{CO}_{2}$ emissions over the 2020Q1-2021Q4. They utilized a global vector autoregressive (GVAR) model, which extracts spatial-temporal connections across diverse countries associated with the global dissemination of economic impact resulting from the COVID-19 diffusion. The obtained outcomes envisage fossil fuel consumption and $\mathrm{CO}_{2}$ emissions to come back to their pre-crisis levels during the two-year horizon despite the significant contractions in the first quarter after the outbreak.

In their study, Meles et al. (2020) examined the consequences of the COVID-19 disaster on the $\mathrm{EU} \mathrm{CO}_{2}$ emissions target for 2030, allowing for an array of scenarios for economic growth. They discover that current climate policy actions could exceed the existing $40 \%$ EU target in 2030 with diminished economic activity following the COVID19 crisis. Their investigation emphasizes that even though current measures will probably decrease emissions by more than $40 \%$ by 2030 following the pandemic, they will not be sufficient to satisfy the targets in Paris agreement.

Hauser et al. (2021) proposed an approach to scrutinize the effect of the COVID-19 on demand for electric power. This approach measures the load saving because of COVID19 at the national level by applying the number of active cases and the particular lockdown time as proxies. The results showed that demand is decreased by about $1-1.7 \mathrm{MW}$ per case in Germany and the UK. They also discussed that the impact of COVID-19 on $\mathrm{CO}_{2}$ emissions in the power sector is expected to be insignificant.

Sikarwar et al. (2021) analyzed the influence of declined activities, due to the COVID-19 pandemic, on $\mathrm{CO}_{2}$ emissions and economic actions. In this study, the information from EU-28, China, the USA, and India were deliberated as benchmark entities, and the trends were inferred to assess the 
global influence. The results showed that the entire global $\mathrm{CO}_{2}$ emissions contraction for January-April 2020 compared to the year before was projected to be around $14 \%$, with an extreme input from the transportation sector.

Andreoni (2021) examined the $\mathrm{CO}_{2}$ emissions because of the socio-economic limitations enforced by the policymakers during the COVID-19 disaster for $23 \mathrm{EU}$ member states. This paper forecasts the $\mathrm{CO}_{2}$ emissions alteration in Europe in the course of the first half of 2020. The obtained results illustrated that $-12.1 \%$ emissions change between January and June 2020 compared to the similar period of the earlier year. This paper underlined that the extent of the COVID-19 influences had fundamentally impacted the CO2 emissions change.

Aljadani et al. (2021) examined COVID-19 relief under the implementation of an $\mathrm{N}$-shaped environmental Kuznets curve in Saudi Arabia. The influences of the price and the rent of oil on $\mathrm{CO}_{2}$ emissions are investigated to characterize the COVID-19 tremor in Saudi Arabia. The results of the autoregressive distributed lag (ARDL) and non-linearautoregressive distributed lag (NARDL) bound testing method specified that under the COVID-19 contagion, the inverted N-shaped environmental Kuznets curve hypothesis is confirmed in the long run. Moreover, they discovered that oil price reinforces the connection of level, quadratic and cubic of economic growth, and environmental quality through oil rent abates this relationship. Also, the longrun occurrences of positive shocks on oil price under the existence of the COVID-19 pandemic are not similar to the negative shocks to $\mathrm{CO}_{2}$ emissions, indicating the presence of asymmetric effects on $\mathrm{CO}_{2}$ emissions in long-run arrangements.

\section{COVID-19 and the analytical methods}

\section{Multifractal analysis}

Choi (2021) analyzed the efficient market hypothesis for several sectors in the US financial market throughout the COVID-19 pandemic to recognize its effects on specific sectors. They outlined the average price for 11 sectors within the S\&P 500 and utilized the multifractal detrended fluctuation analysis (MF-DFA) method to the mean return series to check this hypothesis. The results clarify that the return series illustrate non-persistent and persistent attributes during the GFC and the COVID-19 pandemic, respectively.

Naeem et al. (2021) investigated the relative efficiency of conventional and green bond markets pre and during the COVID-19 pandemic concerning asymmetric multifractal analysis. Precisely, the multifractal scaling behavior is studied independently during upward and downward trends in bond markets with the asymmetric MF-DFA (A-MF-DFA) method. The results approved the existence of asymmetric multifractality in the green and traditional bond markets.

Mensi et al. (2021) examined the effects of COVID-19 on the multifractality of crude oil and gold prices. They applied the A-MF-DFA method to 15-min intraday data. The findings exhibit that multifractality is exceptionally superior in the upside (downside) trend for gold (Brent crude oil) and this excess asymmetry has been heightened during the COVID-19 pandemic. The gold (oil) market was inefficient during downward (upward) trends in advance of the outbreak. However, during the COVID-19 outbreak, they illustrate that the findings have altered. Indeed, they discovered that gold and oil markets have been inefficient, mainly during the current outbreak.

\section{Wavelet analysis}

Goodell and Goutte (2021) applied wavelet methods to daily COVID-19 world deaths and daily Bitcoin prices from 31 December 2019 to 29 April 2020. They discovered that levels of COVID-19 initiated an increase in Bitcoin prices. They infer that the outcomes could be offered to researchers, policymakers, and investment professionals in the financial markets.

Sharma et al. (2021) examined the time-frequency correlation between the quantity of confirmed COVID19 cases, exchange rates, temperature, and stock market return in the 15 highly affected countries through the COVID-19 contagion. They utilized wavelet coherence and partial wavelet coherence methods. Their findings show the following: (i) There is support for cyclical manner between temperature and COVID-19 cases, suggesting that typical daily temperature has a notable influence on the proliferation of the COVID-19 in many countries and (ii) solid connectedness at low frequencies shows that COVID-19 cases have a remarkable long-run effect on the most influenced countries' exchange rate and stock markets returns.

Chien et al. (2021) investigated the time-frequency connection between the COVID-19 pandemic and volatilities in oil price and the stock market, geopolitical risks, and uncertainty in the economic policy in the USA, Europe, and China. The coherence wavelet method and the wavelet-based Granger causality tests are checked to the data. The shortand long-run COVID-19 effects are illustrated differently, and the findings show the decreased industrial productivity, which strengthened with the surge in the pandemic's severeness.

Karamti and Belhassine (2021) investigated the relationship between the COVID-19 pandemic and the most important stock markets within a time-frequency structure. 


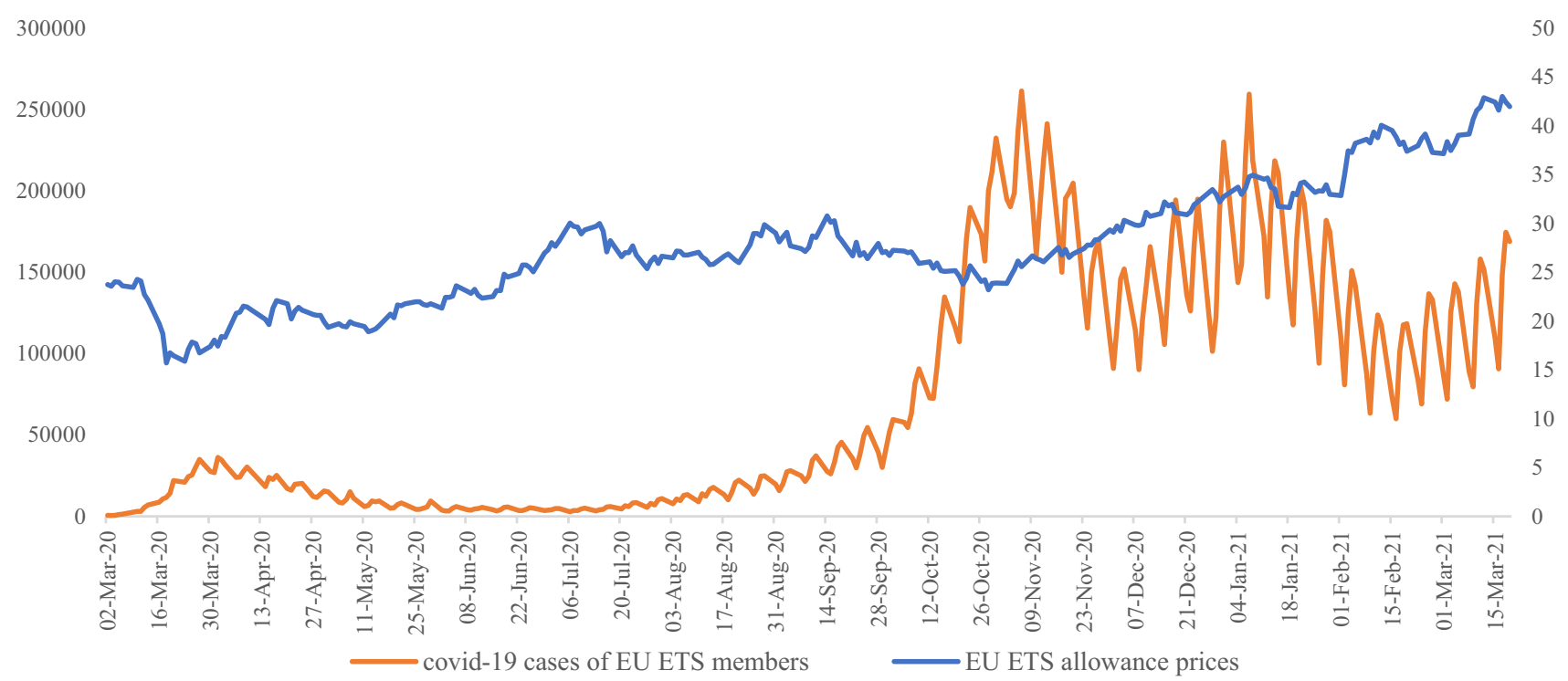

(a)

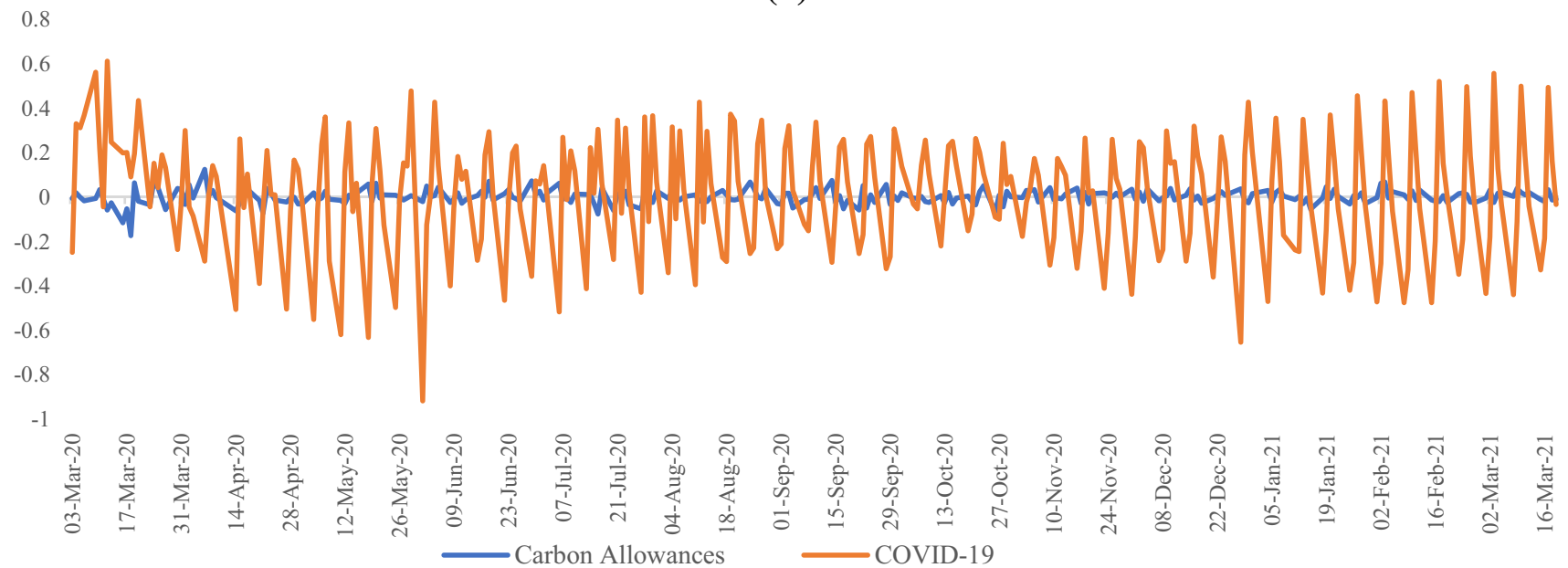

(b)

Fig. 2 a Daily time series of COVID-19 cases (left axis) and EU ETS allowance prices (right axis). b Changes in daily data

Wavelet coherency reveals clear distinctions between the short- and long-term markets' responses. In the short run, they show vigorous co-movements in the first and second waves of the outbreak. Moreover, they show that the COVID-19 fear in the USA dispersed into the international markets.

\section{Data and methodology}

\section{Data and descriptive analysis}

In this part of the study, the statistical examination of data has been considered. The data comprises daily EU ETS allowance prices (EUA) and the number of COVID19 cases. The COVID-19 information obtained from the
World Health Organization (WHO) ${ }^{1}$ and related data for EUA prices is gathered from investing.com. ${ }^{2}$ The data covers from 2 March 2020 to 19 March 2021. Furthermore, the daily changes are considered a logarithmic difference in data, i.e., $y_{t}=\left(\ln x_{t}-\ln x_{t-1}\right)$. The developments in the level and difference of data have been shown in Fig. 2.

The obtained information of descriptive analysis of data has been offered in Table 1. Both data present negative skewness. Moreover, kurtosis is outstanding for both and shows a leptokurtic manner. However, it is incredibly considerable for EUA returns that confirm excess kurtosis. This evidence shows that series are different from Gaussian

\footnotetext{
${ }_{1}$ https://covid19.who.int/info

2 https://www.investing.com/commodities/carbon-emissions
} 
Table 1 Summary statistics of data (daily)

\begin{tabular}{lllllllll}
\hline & Mean & Max & Min & Std. Dev & Skewness & Kurtosis & Jarque-Bera & Prob \\
\hline EUA returns & 0.0021 & 0.1249 & -0.1736 & 0.0324 & -0.4251 & 6.6263 & 156.0711 & 0.0000 \\
COVID-19 cases & 0.0204 & 0.6123 & -0.9182 & 0.2664 & -0.4355 & 2.8889 & 8.6755 & 0.0130 \\
\hline
\end{tabular}

*Jarque-Bera statistic indicates the non-normality of return series at a $1 \%$ significance level
Fig. 3 The $Q-Q$ plot for standardized data
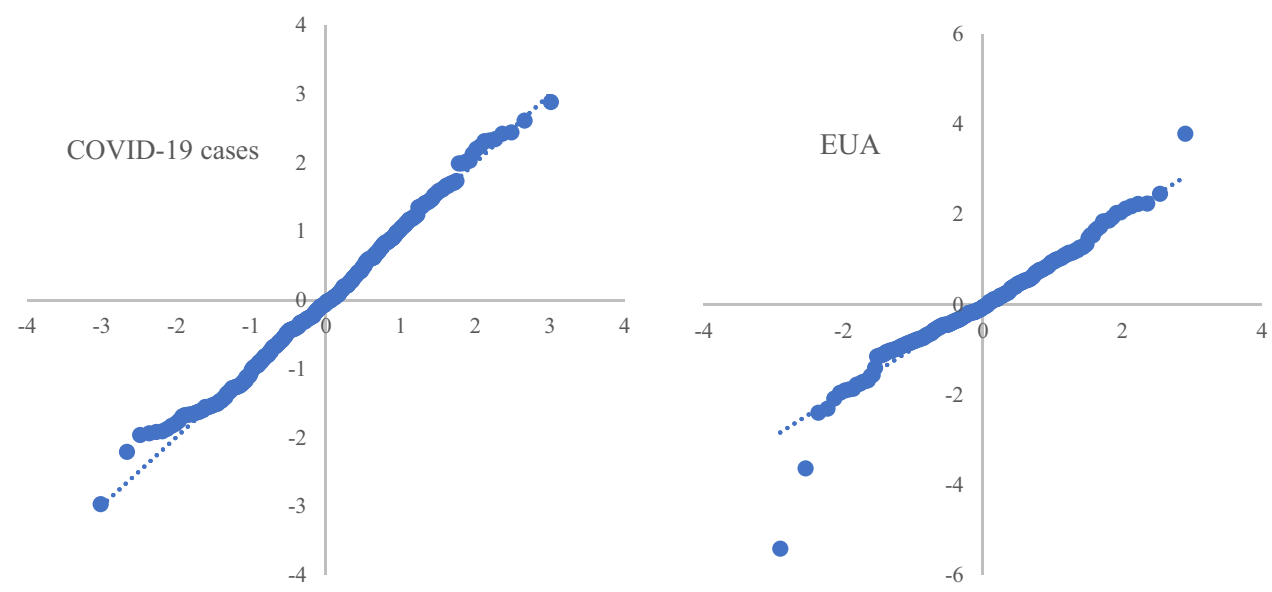

distribution and the meaningful Jarque-Bera test statistics (especially for the EUA returns) verify it.

Furthermore, to better comprehend the manner of each data, we examined the type of distribution and matched it with the Gaussian one by utilizing the $Q-Q$ (quantile-quantile) plot. It compares the prearranged quantities of selected data with quantiles of a particular theoretical distribution (i.e., the Gaussian distribution). The outcomes, which illustrate the distribution divergence from normality, are explained in Fig. 3. The change in COVID-19 cases has the nearest shape of distribution to the normal, and on the contrary, the EUA takes further difference from the normal distribution, respectively. The results are consistent with the Jarque-Bera test statistics exhibited in Table 1 and justify implementing suggested methods in the current study.

\section{Cross dependency and unit root tests}

In this section of the study, the state of dependencies in the error terms was examined through the Pesaran (2004) CD

Table 2 Cross-sectional dependence tests results

\begin{tabular}{|c|c|c|c|c|}
\hline \multirow[b]{2}{*}{ Test statistics } & \multicolumn{2}{|c|}{$\triangle C O V I D-19$ cases } & \multicolumn{2}{|l|}{$\triangle E U A$} \\
\hline & Value & Prob & Value & Prob \\
\hline Pesaran CD & 0.6521 & 0.514 & -0.9107 & 0.362 \\
\hline Breusch-Pagan LM & 360.21 & $0.000 *$ & 66.065 & 0.474 \\
\hline Pesaran scaled LM & 25.608 & $0.000 *$ & 0.0056 & 0.995 \\
\hline
\end{tabular}

Asterisks indicate significance at the $1 \%$ level test, Breusch and Pagan (1980) LM test, and the Pesaran (2004) scaled LM test.

The result of dependencies' tests is indicated in Table 2. It shows that there is cross-dependency for changes in the COVID-19 cases. However, this finding for the changes in the EUA is not significant.

To analyze the behavior of the variables in terms of stationarity, we applied two different unit root tests, including cross-sectionally augmented Im, Pesaran, and Shin (CIPS) (2007) for panel models and Levin et al. (2002). The results of each of these two methods are presented in Table 3. As can be seen from the obtained results, both data present stationary behavior.

\section{Methodology}

In this study, two approaches, multifractal detrending moving average cross-correlation (MF-X-DMA) and wavelet coherence methods, have been proposed to investigate the relationship between $\mathrm{CO}_{2}$ price returns and changes in the

Table 3 Results for unit root tests

\begin{tabular}{lllll}
\hline & \multicolumn{1}{c}{$\Delta$ COVID-19 cases } & \multicolumn{1}{l}{$\Delta E U A$} \\
\hline Test statistics & Value & Prob & Value & Prob \\
Levin et al. (2002) & -8.245 & $0.00 * *$ & -20.476 & $0.00 * *$ \\
Pesaran (2007) CIPS & -4.789 & $0.00 * *$ & -2.961 & $0.03 *$ \\
\hline
\end{tabular}

The $* *$ and $*$ indicate significance at the $5 \%$ and $1 \%$ levels, respectively 
cases of COVID-19. The characteristics of these methods and their advantages are discussed in detail as follows.

\section{MF-X-DMA method}

To analyze the cross-correlation between two series, we used the multifractal detrending moving average cross-correlation (MF-X-DMA) technique developed by Jiang and Zhou (2011). This method detrends the series using moving average and then calculates cross-correlation by combining detrended and multifractal methods.

The method contains the following steps:

Step 1. Consider two time series $x(i)$ and $y(i)$, $c=1,2, \ldots, N$, where $N$ is the length of the series. The sequence of cumulative sums is formulated as follows:

$$
x(c)=\sum_{i=1}^{c} x(i) c=1,2, \ldots, N . y(c)=\sum_{i=1}^{c} y(i) c=1,2, \ldots, N .
$$

Step 2. Measure the moving average for every sequence of cumulative sums in a rolling window by size $\mathrm{v}$ :

$\widetilde{x}_{n}(t)=\frac{1}{v} \sum_{m=-[1 v \theta]}^{[v(1-\theta)]} x(t-m), \widetilde{y}_{n}(t)=\frac{1}{v} \sum_{m=-[v \theta]}^{[v(1-\theta)]} y(t-m) \quad t=v, v+1, \cdots, N$.

where $\theta$ is the state factor with the value fluctuating between zeros to one.

Step 3. Detrend the cumulative sum by differencing the moving average from it:

$w(t)=\left[x_{n}(t)-\tilde{x}_{n}(t)\right]\left[y_{n}(t)-\tilde{y}_{n}(t)\right]$

Step 4. Divide the series $w(t)$, where the size of the sequence is $Z$, into $Z_{v}=[Z / v]$. Non-overlapping boxes equal size $v$. Each box constructed as $\left[g_{n}+1, g_{n}+v\right]$, where $g_{n}=(\mathrm{n}-1)$ and $\mathrm{n}=1,2, \ldots, Z_{v}$.

Step 5. Calculate the cross-correlation for each box:

$F_{n}(v)=\frac{1}{v} \sum_{t=1}^{v} w(t)$

Step 6. Calculate the qth order cross-correlation:

$F_{x, y}(q, v)=\left[\frac{1}{Z_{v}} \sum_{n=1}^{Z_{v}}\left|F_{n}(v)\right|^{q / 2}\right]^{1 / q}$

For $q \neq 0$.

When $q=0$, we have

$F_{x, y}(0, v)=\exp \left[\frac{1}{2 Z_{v}} \sum_{n=1}^{Z_{v}} \ln \left|F_{n}(v)\right|\right]$
Step 7. We have the power-law relationship for diverse quantities of segment size $v$ :

$F_{x, y}(q, v) \sim v^{h_{x, y}(q)}$

Under the general multifractal framework, the multifractal scaling exponent $\tau(q)$ can be applied to illustrate the multifractal character, as follows:

$\tau_{x, y}(q)=q h_{x, y}(q)-D_{f}$

where $D_{f}$ defines the dimension of geometric support of the multifractal measure in terms of fractality. It is straightforward to attain the multifractal spectrum $f(\alpha)$ and the singularity strength function $\alpha(q)$ through the Legendre transform:

$\alpha_{z, w}(q)=\frac{d \tau_{z, w}(q)}{d q} ; f_{z, w}(q)=q \alpha_{z, w}-\tau_{z, w}(q)$

The size of the spectrum defines the power of multifractality and can be clarified by $\Delta \alpha_{z, w}=\max \left(\alpha_{z, w}\right)-\min \left(\alpha_{z, w}\right)$. The broader spectrum shows the robust multifractality nature of the cross-correlated time series.

\section{Wavelet coherence method}

Time and frequency domain methods have been utilized in the literature to discover the causal correlation among the variables. However, it is broadly acknowledged that the conventional methods will not be exact if the time series are non-stationary. Furthermore, the substantial structural breakdown(s) prevailing in the datasets triggers suffering the results of conventional time-domain causality analyses (Adebayo and Odugbesan 2021). Wavelet techniques have been introduced as an imperative innovation to circumvent these obstacles as they let onedimensional time data disintegrate into the two-dimensional time-frequency domain (Kirikkaleli and Gokmenoglu 2020). Indeed, a multi-scale approach offers a typical structure to express frequency-dependent conduct for examining the connection between changes in COVID-19 cases and $\mathrm{CO}_{2}$ price returns in EU ETS and lets us study both the short- and longrun causal relationships between the selected variables.

The wavelet coherence can detect the specific regions in the time-frequency domain where sudden and notable variations occur in the co-movement arrangements of the observed time-series and are analogous to conventional correlation.

The origins of the wavelet $(\psi)$ return to the Morlet wavelet family. There are several types of wavelets with different specifications applied for diverse purposes (Dogra 2017). The mother wavelet implemented in our study is the Morlet wavelet introduced by Goupillaud et al. (1984), which is the most appropriate for identifying 
oscillatory components of a signal. The mentioned wavelet model $(\psi)$ is an extension of the Morlet wavelet shown in Eq. 10:

$\psi(t)=\pi^{-\frac{1}{4}} e^{-i \omega_{0} t} e^{-\frac{1}{2} t^{2}} t=1,2,3, \ldots, T$.

A wavelet is formulated by two separate parameters: location $(p)$ and scale $(y)$. The $p$ parameter has a significant role in discovering the precise position by repositioning the wavelet across time, while $y$ checks the expanded wavelet for confining various frequencies. From the conversion of $\psi$, the $\psi_{p, y}$ is obtained. Equation 11 refers to this transformation:

$\psi_{p, y}(t)=\frac{1}{\sqrt{y}} \psi\left(\frac{t-p}{y}\right), p, y \in \mathbb{R}, y \neq 0$.

$r(t)$ in Eq. 12, showing time series, where a continuous wavelet can be achieved from shows a continuous wavelet from $\psi$ as a function of $p$ and $y$.

$W_{g}(p, y)=\int_{-\infty}^{\infty} r(t) \frac{1}{\sqrt{y}} \psi\left(\frac{t-p}{y}\right) d t$

The reconstructed times series $r(t)$ with the $\psi$ coefficient is

$r(t)=\frac{1}{C_{\psi}} \int_{0}^{\infty}\left[\int_{-\infty}^{\infty}\left|W_{g}(a, b)\right|^{2} d a\right] \frac{d b}{b^{2}}$

To obtain more exhaustive information about the variables, the wavelet power spectrum (WPS) is hired in the current study; WPS gives more information about the scale of the time series:

$W P S_{g}(p, y)=\left|W_{g}(p, y)\right|^{2}$

Based on the principal ambition of the current study, we apply the wavelet coherence approach. The main benefit of this approach over the conventional correlation method is that it lets the study describe any correlation between two time series $r(t)$ and $c(t)$ in joint time-frequency-based causalities. The cross wavelet transform (CWT) of the time series is as follows:

$W_{r c}(p, y)=W_{r}(p, y) \overline{W_{c}(p, y)}$

where $W_{r}(p, y)$ and $W_{c}(p, y)$ represent the CWT of two series $r(t)$ and $c(t)$ respectively. As mentioned through Orhan et al. (2019), the equation of the squared wavelet coherence is

$R^{2}(p, y)=\frac{\mid S\left(\left.y^{-1} W_{r c}(p, y)\right|^{2}\right.}{S\left(y^{-1}\left|W_{r}(p, y)\right|^{2}\right) S\left(y^{-1}\left|W_{c}(p, y)\right|^{2}\right)}$
$S$ shows the smoothing process over time, with $0 \leq R^{2}(p, y) \leq 1$. When $R^{2}(p, y)$ moves toward one, it illustrates that the variables are correlated with a specific scale, which is revealed in the figures in red color and enclosed by a black line. Moreover, if $\mathrm{R}^{2}(\mathrm{p}, \mathrm{y})$ touches zero, indicating no correlation between the series and is presented in blue color (Kirikkaleli and Ozun 2019).

Nevertheless, the calculation of $\mathrm{R}^{2}(\mathrm{p}, \mathrm{y})$ does not allow differentiating the positive correlation from the negative. Torrence and Compo (1998) suggested a tool to scrutinize the wavelet coherence through adjournment indicators in the oscillation of two time series (Rossi and Fattoruso 2017). The equation of the wavelet coherence difference phase is constructed as

$\phi_{r c}(p, y)=\tan ^{-1}\left(\frac{\mathfrak{M}\left\{S\left(y^{-1} W_{r c}(p, y)\right)\right\}}{\mathfrak{R}\left\{S\left(y^{-1} W_{r c}(p, y)\right)\right\}}\right)$

where $\mathfrak{M}$ and $\mathfrak{R}$ denote an imaginary operator and a real operator, respectively.

In the current study, we depict a two-dimensional chart, and the black arrows in this chart illustrate the wavelet coherence phase difference outcomes. When two principal time series show a positive correlation, the wavelet coherence phase difference approaches zero for a certain scale and is echoed by rightward arrows. On the contrary, when two time series show a negative correlation, arrows will be pointing leftward. Moreover, a downward arrow represents that the primary variable leads the second one by $\pi$ and vice versa.

\section{Empirical results}

\section{Cross-correlations}

We begin this section with a statistic test suggested by Podobnik et al. (2009) to check the existence of crosscorrelation statistics between time series $x(j), y(j)$, which cover the similar length $\mathrm{N}$, and functions as follows:

$C_{j}=\frac{\sum_{k=j+1}^{N} x_{k} y_{k-j}}{\sqrt{\sum_{k=1}^{N} x_{k}^{2} \sum_{k=1}^{N} y_{k}^{2}}}$

So the cross-correlation test statistic is

$Q_{c c}(m)=N^{2} \sum_{j=1}^{m} \frac{C_{j}^{2}}{N-j} ; Q_{c c}(m) \sim \chi^{2}(m)$

If the cross-correlation test matches with the $\chi^{2}(m)$ distribution, then there are no cross-correlations between time series; otherwise, the cross-correlations are substantial at a 


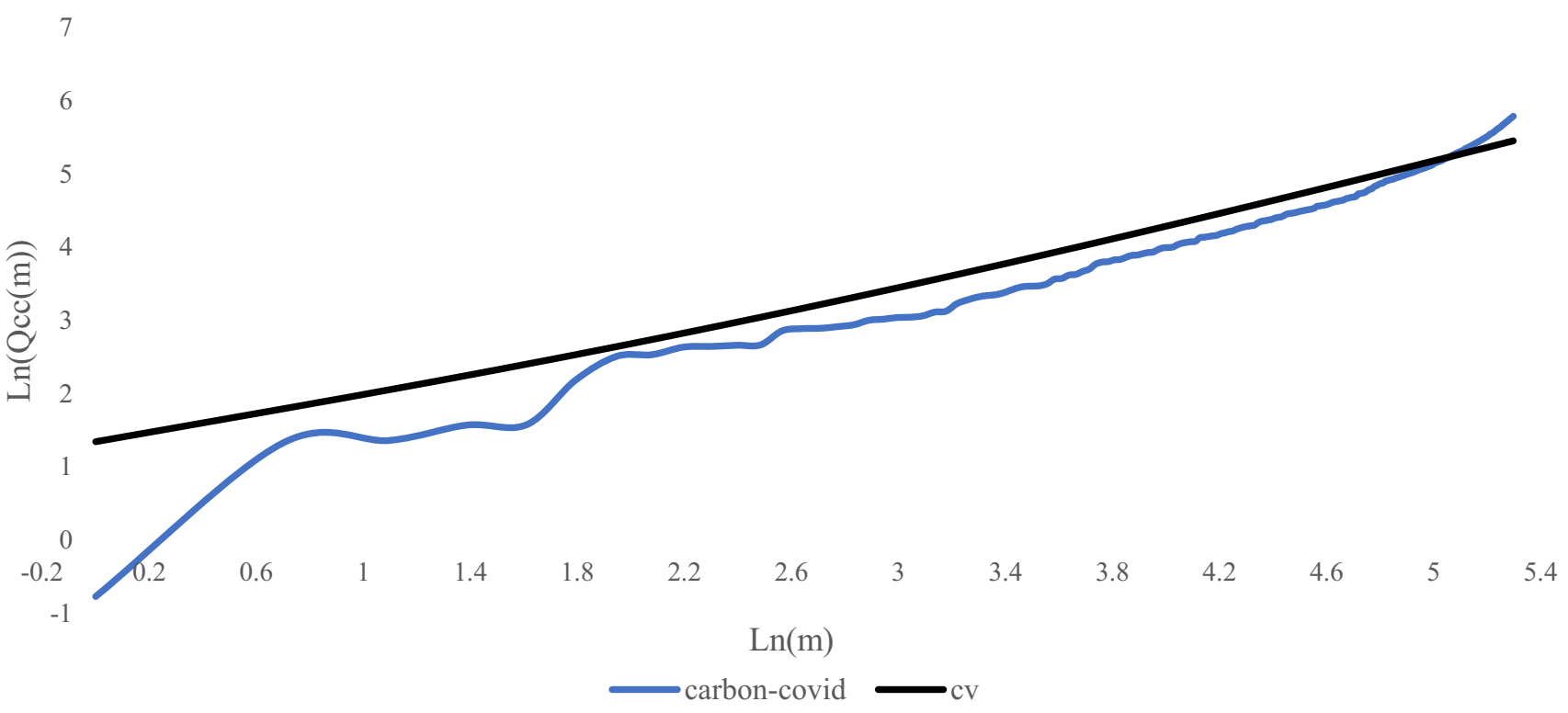

Fig. 4 The cross-correlation statistics for the bivariate series

Fig. 5 The cross-correlation coefficients $\left(\rho_{D M C A}\right)$ for Covid19 and EUA price returns

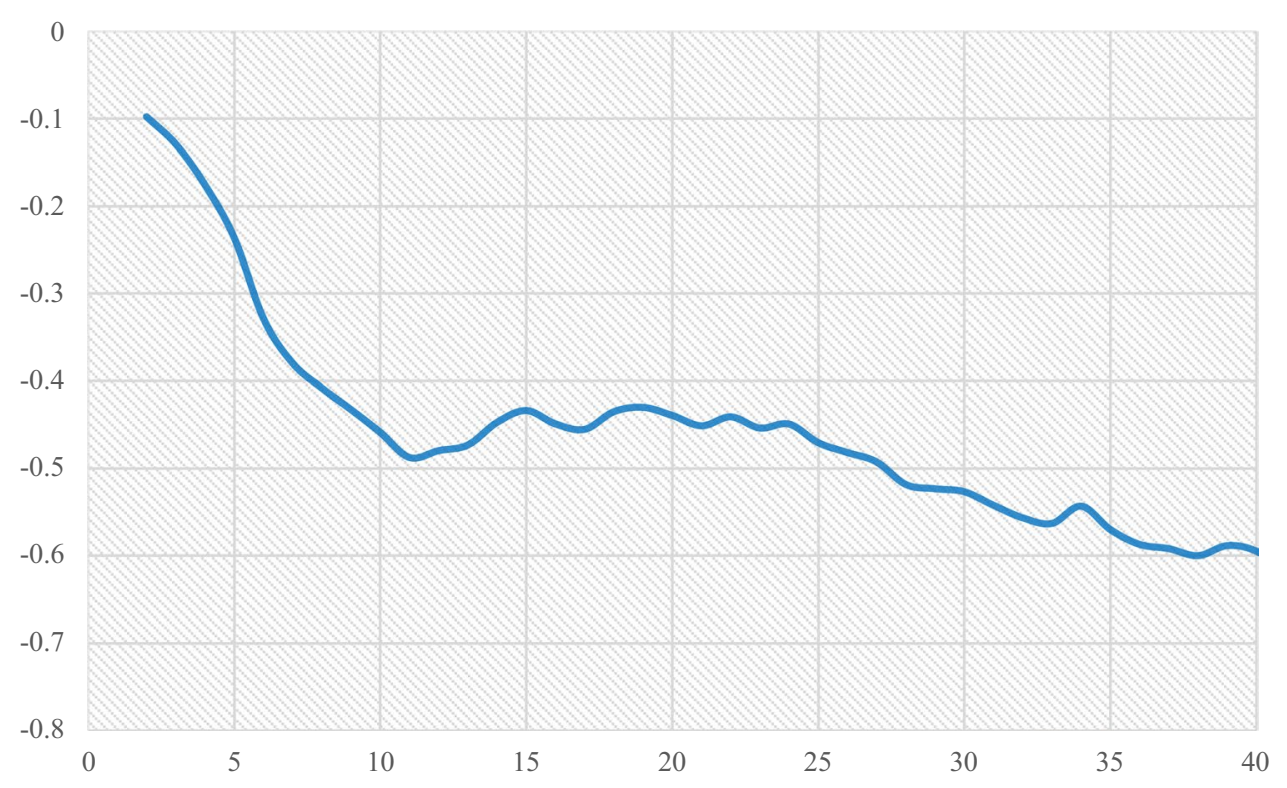

specific significance level. We apply this test on the EUA price returns and COVID-19 cases combinations (Fig. 4) to check whether it exceeds critical value at a five percent significance level in $m$, changing in the range (1 to 200).

In the next step, we apply the DMCA (Kristoufek 2014) method to quantify the existence and the intensity of crosscorrelations. The cross-correlation coefficients are calculated with this formula:

$\rho_{D M C A}=\frac{F_{D M C A}^{2}(s)}{F_{x, D M A}(s) F_{y, D M A}(s)}$
The value of $\rho_{D M C A}$ ranges between -1 and 1 . If $\rho_{D M C A}$ be equal with zero, it confirms that the two series have no cross-correlation. Also, this coefficient separates the level of cross-correlation between the positive and the negative state. We measure the values of $\rho_{D M C A}$ based on diverse window size $v$ for EUA price returns and COVID-19 cases combination. Also, Fig. 5 shows the results for 2 to 40 days of crosscorrelation. Whatever the time window contains extended periods for analyzing are considered, the inverse relationship between the two series shows a more stable arrangement. Therefore, we can conclude that the relationship between series will be lower in the longer term. 


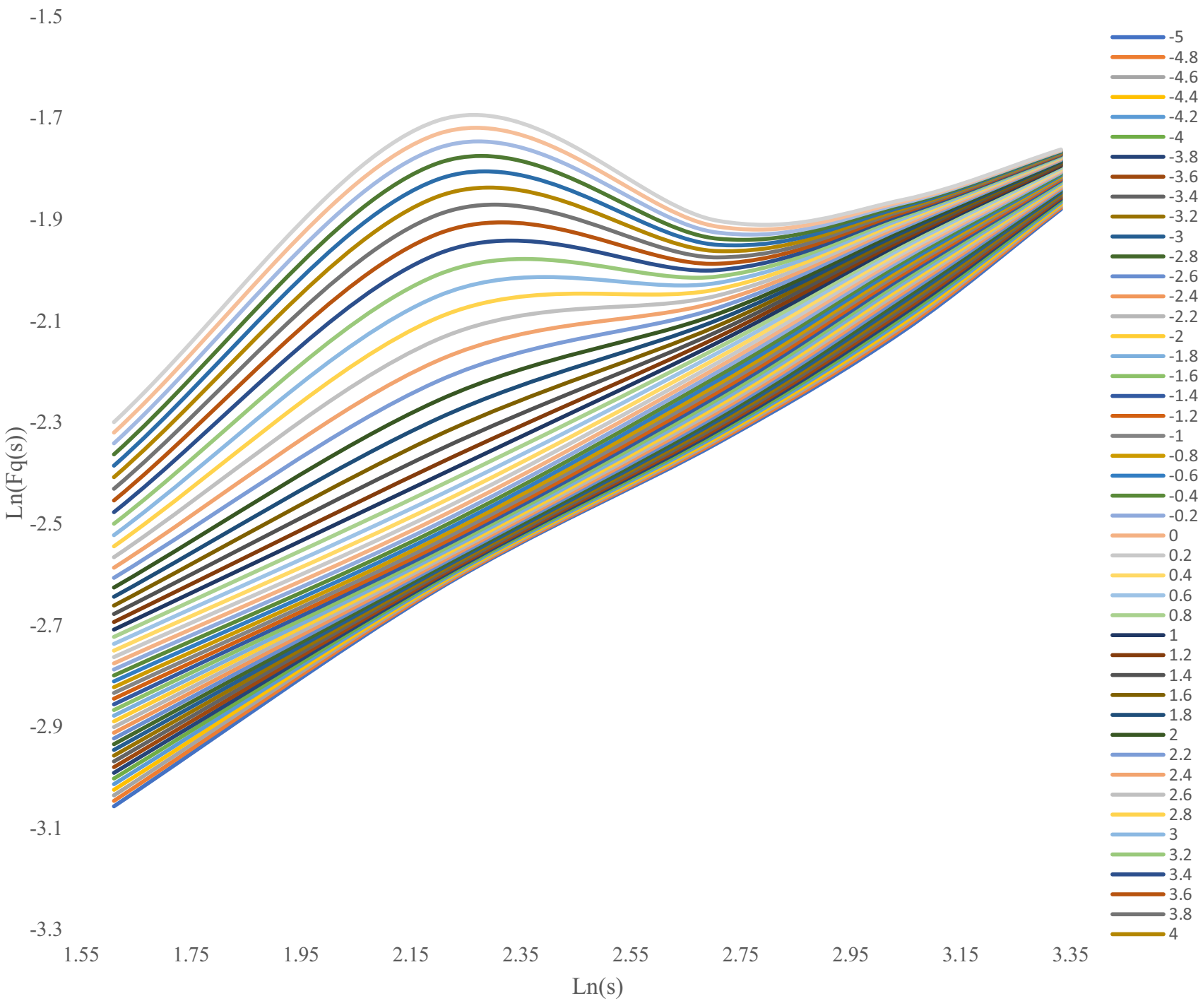

Fig.6 Log-log plots of fluctuation functions $\log (F q(s))$ versus time scale $\log ($ scale) for Covid-19 cases EUA price returns

\section{The analysis of multifractal detrended cross-correlation}

In the following, we implement the MF-X-DMA technique to project the cross-correlation exponent between the series. We set the scale $(v)$ to be $[5,9,15,21,28]$ and $q$ varying from -5 to 5 . Figure 6 illustrates the $\log -\log$ plot of fluctuation function $\operatorname{Ln}(F q(s))$ against scale for EUA price returns and COVID-19 cases combination. It has a positive slope and shows the multifractal property.

Indeed, we can observe more oscillatory behavior in positive and larger numbers of $q$, indicating that the multifractality between the two time series is more significant in this condition. In other words, a large change in the number of COVID19 cases presents a further impact on carbon price fluctuations.
Figure 7a shows the Hurst exponents for EUA price returns-COVID-19 cases combination that, as is clear from the figure, decreases with q changing in the range $[-5,5]$. For $q$ from -5 to 1.4 , Hurst exponents show weak persistent (0.66-0.5), and after $q=1.4$, it drops less than 0.5 , which is as we expected and shows an anti-persistent property. When $q=2$, the power-law exponents are standard Hurst exponents, and here it is equal to 0.473 , which presents weak persistency (see Table 4).

The asymmetric behavior of correlation between two series is also visible in Fig. 7a. When the values of $q s$ are in the negative range, the changing of $h$ is not meaningful, but when we are approaching the positive and significant values of $q s$, the notable changes in $h$ are detectable and have a solid opposite relationship. 


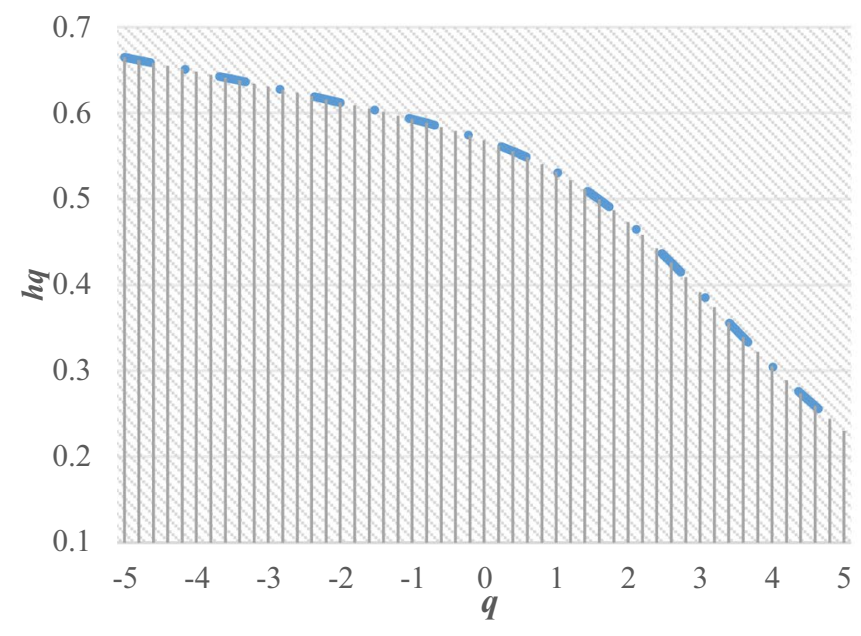

(a)

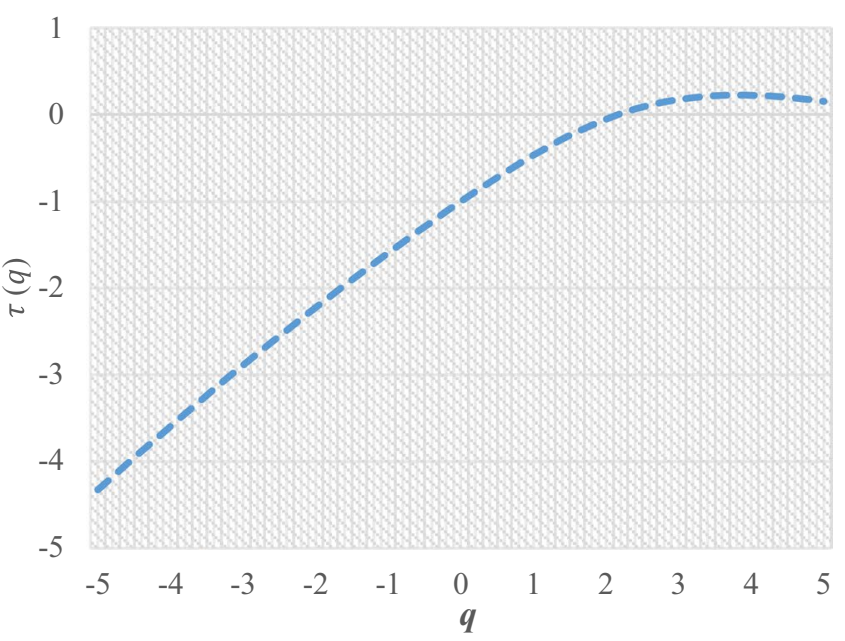

(b)

Fig. 7 a- Hurst exponent $\boldsymbol{h} \boldsymbol{q}(\boldsymbol{q})$ as a function for the EUA price returns and COVID-19 cases combination. b The Renyi exponent $\boldsymbol{\tau}(\boldsymbol{q})$ spectra as a function of $\boldsymbol{q}$

Table 4 The general Hurst exponents for the time series pair

\begin{tabular}{|c|c|c|c|c|c|c|c|c|c|c|c|}
\hline$q$ & -5 & -4 & -3 & -2 & -1 & 0 & 1 & 2 & 3 & 4 & 5 \\
\hline$H q$ & 0.6647 & 0.6480 & 0.6304 & 0.6122 & 0.5925 & 0.5681 & 0.5317 & 0.4730 & 0.3915 & 0.3053 & 0.2304 \\
\hline
\end{tabular}

$H q(2)$ is the standard Hurst exponent

Moreover, positive $q s$ indicate large jumps or high volatility in the time series, so it can be concluded that $\mathrm{CO}_{2}$ price returns are affected by the jumps in the COVID19 cases. In return, it is slightly affected by experiencing small jumps, stagnation, and stability in the number of COVID-19 cases.
As follows, the findings of the Renyi exponent $(\tau(q))$ spectra in Fig. $7 \mathrm{~b}$ verify the presence of multifractality property between EUA price returns and COVID-19 cases.

Moreover, to show the amount of multifractal property, we have drawn $f(\alpha)$ against $\alpha$ (multifractal spectra) in Fig. 8 .
Fig. 8 The multifractal spectra, $f(\alpha)$, for EUA price returns and COVID-19 cases combination

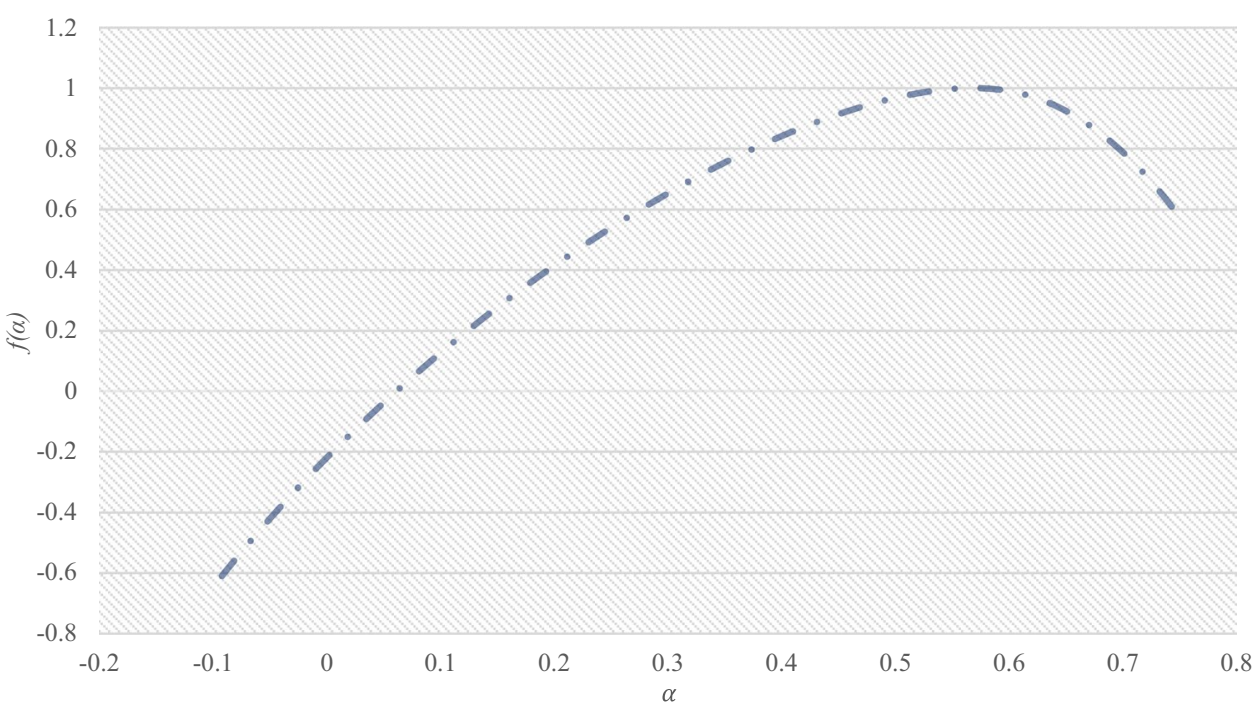




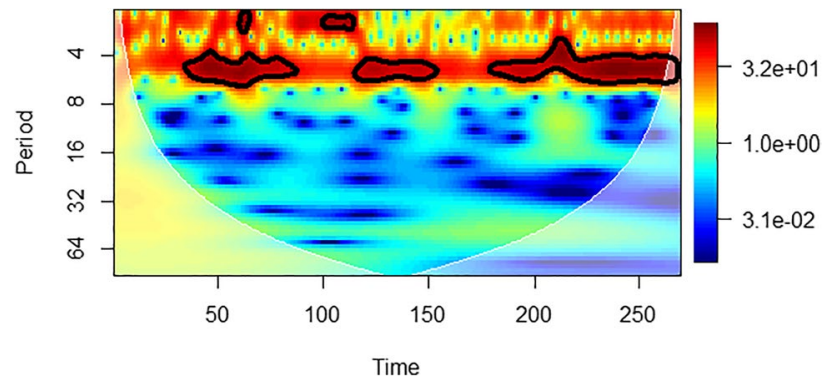

Fig. 9 WPS for daily changes of COVID-19

\section{Wavelet analysis}

This section applies continuous WPS and coherence methodologies between changes in the COVID-19 cases and returns of $\mathrm{CO}_{2}$ prices in EU ETS to examine the interconnection between them. The wavelet power spectrum for each data has been demonstrated in Figs. 9 and 10.

The time scale is offered on the horizontal axis, while the frequency scale is characterized through the vertical axis. The frequency scale spans high-frequency (2-4 days) to low-frequency (32-64 days). A color-coded (blue to red color; from low to high) has been suggested to determine the spectra intensity. The black contour presents the WPS at 5\% significance level.

Furthermore, the arrows offer the course of interconnection and causality relationships (Pal and Mitra 2019; He et al. 2021). Arrows directing to the right $(\rightarrow)$ (in-phase) and the left $(\leftarrow)$ (out of phase) specify that COVID-19 cases and returns of $\mathrm{CO}_{2}$ prices are positively and negatively correlated, respectively. Also, the $\nearrow$ and $\swarrow$ arrows indicate that returns of $\mathrm{CO}_{2}$ prices lead changes in COVID-19 cases, whereas the $\searrow$ and $\nwarrow$ arrows designate that vice versa. The straight-up $(\uparrow)$ and down $(\downarrow)$ arrows indicate that the returns of $\mathrm{CO}_{2}$ prices are leading and lagging, respectively.

Figure 10 represents the WPS for the $\mathrm{CO}_{2}$ price returns, which illustrates that the variable is considerably volatile during the early stages of the COVID-19 outbreak (particularly in the first 75 days, coinciding with the initial wave of the COVID-19 pandemic). Moreover, it exhibits high power in 0-16 scales in

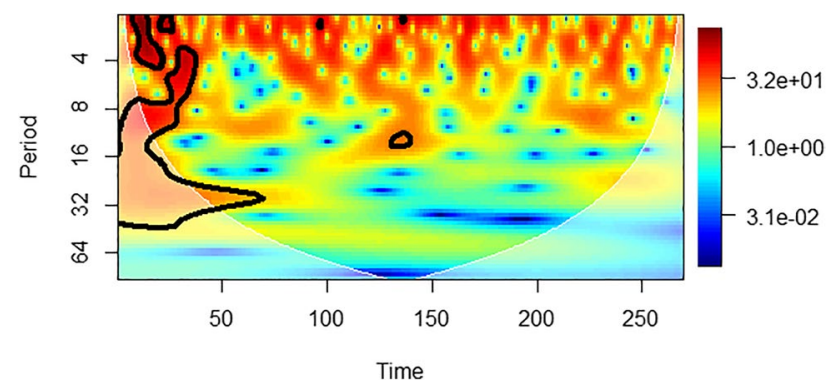

Fig. 10 WPS for daily return of $\mathrm{CO}_{2}$ prices the whole period, specifying that the COVID-19 catastrophe meaningfully influenced the profile of the $\mathrm{CO}_{2}$ price returns.

In Fig. 11 and the early COVID-19 outbreak, we see a strong (negative) relationship between variables. Also, when we focus on the direction of the signs, we can infer that two variables have a negative relationship in all periods. In addition, in the range of 16-32 days, the COVID-19 variable is leading the $\mathrm{CO}_{2}$ price returns. By looking carefully in Fig. 11, we can also see the several distinct islands in which the correlation between the selected data is strong, and this strong correlation is observed throughout the whole period of study; mainly in the range of 0-2 and 4-8 days (low-frequency scales).

\section{Policy implications}

The COVID-19 pandemic has once more proved that substantial shocks could deliver significant influences on the energy transition. The problem is how to constitute such tremors when planning policies for the long run. The transition will take a long span of years, and therefore there will be more shocks. Thus far, procedures to form these resilient policies rarely have been respected in the designing process. Nevertheless, the recent challenge highlights that supposing perpetual steadiness is a misbelief and policies that depend on it overlook two considerable risks: (I) If policy incentives rely on economic situations, recessions could rigorously hinder investments in green technologies. (II) If the incentives do not adjust to challenging existing situations and objectives, policies can be abolished when priorities for policymakers change and the economic condition is not in good shape. Each of two risks may threaten transition to a low-carbon state or, at best, interrupt it noticeably.

We can suggest making policies flexible to shocks by arrangements that can lessen the abovementioned risks. One instance of such policies that ought to become adaptive in that event is policies about carbon pricing (Steffen et al. 2020). Carbon pricing is destined to become a crucial part of the

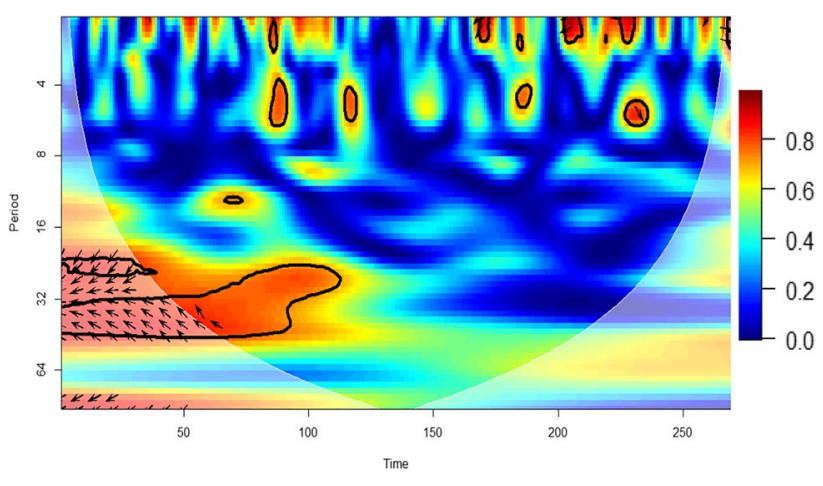

Fig. 11 Wavelet coherence between changes of COVID-19 and return of $\mathrm{CO}_{2}$ prices 
energy transition scheme, and it is clear that an incredibly transparent and efficient mechanism to discover prices helps for any decision-making at different levels (from traders in the market to policymakers). An onward approach to make an adaptive carbon pricing contains mixture mechanisms. These could either be the integration of taxes with an environmental scheme, as only suggested for the USA (Brooks and Keohane 2020), or implementing programs like cap-and-trade concerning a price collar, just lately offered for Germany (Edenhofer et al. 2019). The common feature of both schemes is that prices inevitably adapt to new situations-and the extent of change echoes environmental worries accompanied by potential shocks. Generally, these cases explain the central concept of resilient policies: to justify an equilibrium between the two risks as mentioned above, guaranteeing that in the occurrence of shocks, the policy is neither undermined in a way that imperils the transition (e.g., through weakening green investors' confidence) nor demolished it (Polzin et al. 2019).

Nonetheless, we can mention some supportive actions for improving the scheme and reconstructing it for more resiliency in the face of possible shocks in the future:

- The strengthening the Market Stability Reserve (MSR) (e.g., through declining threshold needs to be established) and increasing the linear reduction factor (LRF) for moving towards decarbonization (especially in the power and industrial sectors).

- Implementing a carbon price floor as a complementary policy to the MSR and combining it with a quantity-based design to ensure support in low-carbon investments.

- Another policy action scheduled for 2021 is introducing a carbon border adjustment mechanism (CBAM) by the EU to achieve the targets in the European Green Deal and become the world's first climate-neutral bloc by 2050. One of the areas proposed in CBAM is reviewing and possibly revising all relevant climate-related policy instruments, including ETS.

\section{Conclusions}

All ETSs are now under pressure because of the COVID19 pandemic, and the macroeconomic and political circumstances have radically altered, and energy policies may require to be adjusted to the latest conditions. In addition, deep-rooted and prearranged energy policies are challenged, principally by the severely involved industries in the recent crisis. On the other hand, achieving the goal of the sustainable energy transition is a multifaceted social, political, economic, and technological challenge. In this regard, the COVID-19 pandemic presents new challenges for achieving this goal. Also, it shows us to prioritize policies that support the curtailment in environmental risks before they strike. Meanwhile, perhaps surprisingly, the COVID-19 crisis is the perfect time to present carbon pricing more broadly to incentivize a more sustainable future.

By looking at the developments that have been taken place in the EU ETS, we can observe that the prices remain high during the ongoing public health and economic crisis. It is a good sign that the reforms made to the system within the last five years are doing their job, keeping the market stable and more resistant to exogenous shocks. Considering the developments outlined in the study, the recovery of carbon prices under the EU ETS following the onset of the COVID-19 crisis shows that the scheme can resist economic shocks, and some studies believe that EU ETS has passed the resilience test coronavirus pandemic (ICAP 2021). Moreover, the obtained results in the current study showed a notable effect of the COVID-19 pandemic on the carbon market, and also we can infer that the significant changes in the number of COVID-19 patients lead to a stronger relationship between the two series.

In conclusion, by looking at the carbon prices in the EU ETS, we can point to the need to strengthen the scheme to be more resilient and be sustained effectively in the future and in the face of possible shocks. With all the actions being undertaken to fight against the COVID-19 pandemic, it will be critical to assure that EU climate policies are prepared and not been undermined and the scheduled stimulus packages for economic recovery should also continue to deliver support to the plans like the EU Green Deal.

Author contribution MMG: Conceptualization, investigation, methodology, formal analysis, visualization, writing the original draft. RK: Calculation, calibration, visualization. SB: Review, editing, and made suggestions to improve the quality of the manuscript.

Data availability The datasets used/or analyzed during the current study are available upon request.

\section{Declarations}

Ethics approval Not applicable.

Consent to participate Not applicable.

Consent for publication Not applicable.

Conflict of interest The authors declare no competing interests.

\section{References}

Adebayo TS, Odugbesan JA (2021) Modeling CO2 emissions in South Africa: empirical evidence from ARDL based bounds and wavelet coherence techniques. Environ Sci Pollut Res 28:9377-9389

Aktar MA, Alam MM, Al-Amin AQ (2021) Global economic crisis, energy use, $\mathrm{CO} 2$ emissions, and policy roadmap Amid 
COVID-19. Sustain Prod Consum 26:770-781. https://doi.org/ 10.1016/j.spc.2020.12.029

Aljadani A, Toumi H, Toumi S, Hsini M, Jallali B (2021) Investigation of the N-shaped environmental Kuznets curve for COVID-19 mitigation in the KSA. Environ Sci Pollut Res, 1-20

Andreoni V (2021) Estimating the European CO2 emissions change due to COVID-19 restrictions. Sci Total Environ 769:145115

Asongu S, El Montasser G, Toumi H (2016) Testing the relationships between energy consumption, $\mathrm{CO} 2$ emissions, and economic growth in 24 African countries: a panel ARDL approach. Environ Sci Pollut Res 23(7):6563-6573

Breusch T, Pagan AR (1980) The Lagrange multiplier test and its application to model specifications in econometrics. Rev Econ Stud 47:239-253

Brooks SA, Keohane NO (2020) The political economy of hybrid approaches to a US carbon tax: a perspective from the policy world. Rev Environ Econ Policy 14:67-75

Chien F, Sadiq M, Kamran HW, Nawaz MA, Hussain MS, Raza M (2021) Co-movement of energy prices and stock market return: environmental wavelet nexus of COVID-19 pandemic from the USA, Europe, and China. Environ Sci Pollut Res. 1-15.

Choi S-Y (2021) Analysis of stock market efficiency during crisis periods in the US stock market: differences between the global financial crisis and COVID-19 pandemic. Phys A Stat Mech its Appl. 574:125988

Dechezlepretre A, Kozluk T, Elgouacem A, Kruse T (2020) COVID19 and the low-carbon transition: impacts and possible policy responses.

Dogra A (2017) Performance comparison of different wavelet families based on bone vessel fusion. Asian J. Pharm. Free full text Artic. from Asian J Pharm 10.

Edenhofer O, Flachsland C, Kalkuhl M, Knopf B, Pahle M (2019) Options for a carbon pricing reform

European Commission (2018) EC - European Commission. Revision for phase 4 (2021-2030). https://ec.europa.eu/clima/policies/ets/ revision_en. Accessed 20 Sep 2021

Evans S (2020) Analysis: Coronavirus set to cause largest ever annual fall in $\mathrm{CO} 2$ emissions. Carbon Br. 9.

Goodell JW, Goutte S (2021) Co-movement of COVID-19 and Bitcoin: evidence from wavelet coherence analysis. Financ Res Lett. 38:101625

Goupillaud P, Grossmann A, Morlet J (1984) Cycle-octave and related transforms in seismic signal analysis. Geoexploration 23:85-102

Hale T, Petherick A, Phillips T, Webster S (2020) Variation in government responses to COVID-19. Blavatnik Sch Gov Work Pap 31:2011-2020

Hauser P, Schönheit D, Scharf H, Anke CP, Möst D (2021) Covid-19's impact on European power sectors: an econometric analysis. Energies 14(6): 1639

He X, Gokmenoglu KK, Kirikkaleli D, Rizvi SKA (2021) Co-movement of foreign exchange rate returns and stock market returns in an emerging market: Evidence from the wavelet coherence approach. Int J Financ Econ

Hosseini SE (2020) An outlook on the global development of renewable and sustainable energy at the time of Covid-19. Energy Res Soc Sci. 68:101633

ICAP (2021) Emissions trading worldwide: status report 2021. https://icapcarbonaction.com/en/icap-status-report-2021. Accessed March 2021

IEA (2020) Global Energy Review 2020. https://www.iea.org/repor ts/global-energy-review-2020. Accessed July 2020

IMF (2021). World economic outlook: managing divergent recoveries. April 2021.

Jiang P, Van Fan Y, Klemeš JJ (2021) Impacts of COVID-19 on energy demand and consumption: challenges, lessons and emerging opportunities. Appl Energy 116441.
Jiang Z-Q, Zhou W-X (2011) Multifractal detrending moving-average cross-correlation analysis. Phys Rev E 84:16106

Kamaludin K, Sundarasen S, Ibrahim I (2021) Covid-19, Dow Jones and equity market movement in ASEAN-5 countries: evidence from wavelet analyses. Heliyon 7:e05851

Karamti C, Belhassine O (2021) COVID-19 pandemic waves and global financial markets: evidence from wavelet coherence analysis. Financ Res Lett 102136.

Kirikkaleli D, Gokmenoglu KK (2020) Sovereign credit risk and economic risk in Turkey: empirical evidence from a wavelet coherence approach. Borsa Istanbul Rev 20:144-152

Kirikkaleli D, Ozun A (2019) Co-movement of political risk and sovereign credit risk: a wavelet coherence analysis for Argentina, Brazil, and Venezuela. Soc Sci Q 100:2094-2114

Klenert D, Funke F, Mattauch L, O'Callaghan B (2020) Five lessons from COVID-19 for advancing climate change mitigation. Environ Resour Econ 76:751-778

Kristoufek L (2014) Detrending moving-average cross-correlation coefficient: measuring cross-correlations between non-stationary series. Phys A Stat Mech Its Appl 406:169-175

Kuzemko C, Bradshaw M, Bridge G, Goldthau A, Jewell J, Overland I, Scholten D, Van de Graaf T, Westphal K (2020) Covid-19 and the politics of sustainable energy transitions. Energy Res. Soc. Sci. 68:101685

Levin A, Lin CF, Chu CSJ (2002) Unit root tests in panel data: asymptotic and finite-sample properties. Journal of Econometrics 108(1):1-24

Meles TH, Ryan L, Wheatley J (2020) COVID-19 and EU climate targets: can we now go further? Environ Resource Econ 76(4):779-787

Mensi W, Vo XV, Kang SH (2021) Upside-downside multifractality and efficiency of green bonds: the roles of global factors and COVID-19. Financ Res Lett 101995.

Mintz-Woo K, Dennig F, Liu H, Schinko T (2020) Carbon pricing and COVID-19. Clim Policy 1-9.

Mirzaee Ghazani M, Jafari MA (2021) The efficiency of CO2 market in the phase III EU ETS: analyzing in the context of a dynamic approach. Environ Sci Pollut Res. 1-16.

Naeem MA, Farid S, Ferrer R, Shahzad SJH (2021) Comparative efficiency of green and conventional bonds pre-and during COVID19: an asymmetric multifractal detrended fluctuation analysis. Energy Policy 153:112285

OECD (2020) Evaluating the initial impact of COVID-19 containment measures on economic activity.

Orhan A, Kirikkaleli D, Ayhan F (2019) Analysis of wavelet coherence: service sector index and economic growth in an emerging market. Sustainability 11:6684

Pal D, Mitra SK (2019) Oil price and automobile stock return co-movement: a wavelet coherence analysis. Econ Model $76: 172-181$

Pesaran MH (2004) General diagnostic tests for cross section dependence in panels. Cambridge Working Paper in Economics, 0435(3), 1-39.

Pesaran MH (2007) A simple panel unit root test in the presence of cross-section dependence. Journal of Applied Econometrics, 22(2), 265-312. http://www.jstor.org/stable/25146517

Podobnik B, Grosse I, Horvatić D, Ilic S, Ivanov PC, Stanley HE (2009) Quantifying cross-correlations using local and global detrending approaches. Eur Phys J B 71:243

Polzin F, Egli F, Steffen B, Schmidt TS (2019) How do policies mobilize private finance for renewable energy?-A systematic review with an investor perspective. Appl Energy 236:1249-1268

Rossi M, Fattoruso G (2017) The EMH and the market anomalies: an empirical analysis on Italian stock market. Int J Manag Financ Account 9:222-241 
Sharma GD, Tiwari AK, Jain M, Yadav A, Erkut B (2021) Unconditional and conditional analysis between covid-19 cases, temperature, exchange rate and stock markets using wavelet coherence and wavelet partial coherence approaches. Heliyon 7:e06181

Sikarwar VS, Reichert A, Jeremias M, Manovic V (2021) COVID-19 pandemic and global carbon dioxide emissions: a first assessment. Sci Total Environ 794:148770

Smith LV, Tarui N, Yamagata T (2021) Assessing the impact of COVID-19 on global fossil fuel consumption and $\mathrm{CO} 2$ emissions. Energy Econ 97:105170

Steffen B, Egli F, Pahle M, Schmidt TS (2020) Navigating the clean energy transition in the COVID-19 crisis. Joule 4:1137-1141
Torrence C, Compo GP (1998) A practical guide to wavelet analysis. Bull Am Meteorol Soc 79:61-78

UNECE (2020) Pathways to sustainable energy-accelerating energy transition in the UNECE region. https://unece.org/fileadmin/ DAM/energy/se/pdfs/CSE/Publications/Final_Report_Pathw aysToSE.pdf. Accessed August 2020

Publisher's note Springer Nature remains neutral with regard to jurisdictional claims in published maps and institutional affiliations. 